\title{
RESPONSABILIDAD OBJETIVA RELATIVA A PROPÓSITO DE LA REFORMA ADMINISTRATIVA CONSTITUCIONAL
}

\section{RELATIVE STRICT LLABILITY FOR THE PURPOSE OF THE CONSTITUTIONAL ADMINISTRATIVE REFORM}

\author{
Luis Miguel Facundo Niño de Guzmán ${ }^{1}$ \\ Docente \\ Universidad de San Martín de Porres \\ lfacundo@usmp.pe \\ Perú, Lima
}

\section{SUMARIO}

- Principio de culpabilidad en el derecho administrativo sancionador peruano

- Responsabilidad Subjetiva y Objetiva en el marco de la filosofía del derecho y teoría general del derecho

- Responsabilidad Objetiva en el marco del derecho constitucional peruano y comparado

- Responsabilidad Objetiva en el marco de la Corte Interamericana de Derechos Humanos (CIDH)

- Reforma constitucional a fin de explicitar la potestad sancionadora de la Administración Pública y la Responsabilidad Objetiva

- Ley de Desarrollo Constitucional a fin de establecer los límites de la Responsabilidad Objetiva Relativa

- Conclusiones

\section{RESUMEN}

En el presente artículo, el autor realiza un análisis de la constitucionalidad de la responsabilidad objetiva relativa en el derecho administrativo sancionador, pues si bien a nivel legal la LPAG ha consagrado la excepcionalidad de la responsabilidad objetiva, sin embago nuestro Tribunal Constitucional siempre ha consagrado la proscripción de la responsabilidad objetiva por ser incompatible con el principio de culpabilidad. En ese sentido, se analizarán diversos puntos como la Filosofía del Derecho, Teoría General del Derecho, Rango del Principio de Culpabilidad, Derecho Comparado, entre otros aspectos, para poder llegar a plantear una reforma constitucional a fin de explicitar la potestad sancionadora de la Administración Pública y constitucionalizar la excepcionalidad de la responsabilidad objetiva relativa con su respectiva ley de desarrollo constitucional.

\section{ABSTRACT}

In this article, the author performs an analysis of the constitutionality of the relative strict liability in the sanctioning administrative law, because although at the legal level the LPAG has enshrined the exceptionality of strict liability, however our Constitutional Court has always enshrined the prohibition of strict liability for being incompatible with the principle of culpability. In that sense, various points such as the Philosophy of Law, General Theory of Law, Range of Guilt Principle, Comparative Law, among other aspects, will be analyzed in order to be able to propose a constitutional reform in order to specify the sanctioning authority of the Administration Public and constitutionalize the exceptionality of the relative strict responsibility with its respective law of constitutional development.

\footnotetext{
1 Egresado del Doctorado en Derecho por la Universidad de San Martín de Porres. Maestro en Derecho de los Negocios y Abogado por la Universidad de San Martín de Porres.
} 


\section{PALABRAS CLAVE}

Principio de Culpabilidad; Responsabilidad Subjetiva; Responsabilidad Objetiva; Responsabilidad Objetiva Relativa; Eximentes de Responsabilidad; Ponderación; Derecho Administrativo Sancionador; Reforma Constitucional y Ley de Desarrollo Constitucional.

\section{KEY WORDS}

Culpability Principle; Subjetive Liability; Strict Liability; Relative Strict Liability; Exempt from Liability; Weighting; Sanctioning Administrative Law; Constitutional Reform and Constitutional Development Law.

\section{PRINCIPIO DE CULPABILIDAD EN EL DERECHO ADMINISTRATIVO SANCIONADOR PERUANO}

\section{Principio de Culpabilidad: Subprincipios}

El Principio de Culpabilidad denominando principio complejo, continene cuatro (04) principios o subprincipios, tal como desarrolla Gómez (2010), siendo los relevantes para el presente trabajo, el principio de personalidad de las sanciones (no responsabilidad por hechos ajenos); y por otro lado el "principio de imputación o responsabilidad subjetiva (exigencia de dolo o culpa) y por ende la proscripción de responsabilidad objetiva" (Gómez, 2010, página 386).

Por lo que la imputación o responsabilidad subjetiva como manifestación del principio de culpabilidad, según la posición dominante de la doctrina nacional aplicable al derecho administrativo sancionador, requeriría ir más allá de la realización de la conducta o efecto dañoso, tal como afirma Morón (2017).

\section{Principio de culpabilidad y la unidad del derecho sancionador o ius puniendi}

Asumiendo, la posición mayoritaria de la doctrina nacional, de que existe unidad del derecho sancionador tanto del Derecho Penal como Derecho Administrativo Sancionador, nos llevaría aplicar prima facie los mismos principios y como dice Rojas (2015) al "aplicar el principio de culpabilidad (y por ende el sub principio de responsabilidad subjetiva) trae como consecuencia lógica la aplicación de la proscripción de responsabilidad objetiva" (página172).

En esa línea, nuestro Tribunal Constitucional, ha asumido tal como lo han hecho sus referentes Tribunal Constitucional Español y Corte Constitucional Colombiana, la tesis de la unidad del derecho sancionador y por ende la aplicación del principio de culpabilidad en el Derecho Administrativo Sancionador, tal como se indica en la STC 2050-2002-AA/TC que dice:

Sobre el particular, es necesario precisar que los principios de culpabilidad, legalidad, tipicidad, entre otros, constituyen principios básicos del derecho sancionador, que no sólo se aplican en el ámbito del derecho penal, sino también en el del derecho administrativo sancionador. (Fundamento 8)

Por otro, lado si vamos al derecho comparado, en la doctrina española, si se parte como dice Gómez (2010), de la "identidad ontológica entre infracciones administrativas y penales, trae como consecuencia de que la infracción administrativa tenga en su estructura el elemento de culpabilidad" (página 460).

Sin embargo, en el derecho administrativo sancionador vemos un nudo gordiano parafraseando a Nieto (2012), pues por un lado se trata de incorporar el principio de culpabilidad y por ende el sub principio de responsabilidad subjetiva, sin embargo no se sabe cómo aceptar o sostener la aplicación de la excepcionalidad de la responsabilidad objetiva, ya que como dice Morón (2017), “el mismo trae diferencias conceptuales y prácticas en el derecho administrativo sancionador" (página 445-446), lo que se manifiesta en solo sustentarlo como un giro pragmático.

Sin perjuicio, de ello si bien coincido con la tesis de la unidad del derecho sancionador, que permitiría aplicar en el derecho administrativo sancionador sus principios con matices ${ }^{2}$, sin embargo considero que se debe ir más allá, y propugnarse la autonomía científica del derecho administrativo sancionador (por ejemplo: Derecho del Consumidor), ya que la dependencia del Derecho Penal lleva a aplicar la proscripción de responsabilidad objetiva (los

2 Aplicación con matices de los Principios del Derecho Sancionador al Derecho Administrativo Sancionador, es recogido en los numerales 16,18 y 19 de la Consulta Juridica No 005-2015-JUS/DGDOJ de la actual Direccion General de Desarrollo Normativo y Calidad Regulatoria. 
matices no permitirían su establecimiento por inaplicar la responsabilidad subjetiva y por ende el principio de culpabilidad) y la dependencia del Derecho Civil lleva aplicar la regla de responsabilidad objetiva como regla general; ya que con esta autonomía a nivel dogmático daría contenido al giro pragmático que se ha propuesto, pues permitiría romper el dogma de la proscripción de la responsabilidad objetiva pero establecería su naturaleza excepcional por ser una medida restrictiva del ius puniendi, porque el objetivo principal no es proscribir las medias restrictivas y discrecionales, sino la arbitrariedad del ius puniendi del Estado.

\section{Principio de culpabilidad y su regulación en la Ley del Procedimiento Administrativo Sancionador (LPAG)}

Es necesario indicar que antes de la modificación realizada por el Decreto Legislativo $\mathrm{N}^{\circ} 1272$, a la Ley del Procedimiento Administrativo General (LPAG), tal como decía Baca (2010) "no había positivizado de manera expresa el Principio de Culpabilidad ni el de Responsabilidad Subjetiva" (página 7). Pero si alguno de sus subprincipios, ya que por un lado se había positivizado el subprincipio de personalidad de las sanciones (entendido como causalidad) al momento de la determinación de la infracción y por otro lado al momento de graduación de la sanción (intencionalidad como elemento de razonabilidad).

Siendo que la regla general era la responsabilidad objetiva, al momento de determinar la infracción administrativa, basándose en que la misma derivaba en el principio de causalidad, por el silencio y el carácter de la LPAG.

Sin embargo, mediante el Decreto Legislativo $\mathrm{N}^{\circ} 1272$ se establece de manera expresa bajo la denominación del Principio de Culpabilidad el Sub Principio de Responsabilidad Subjetiva (numeral 10 del artículo $230^{3}$ ), siendo que la evolución del principio de culpabilidad, se puede apreciar en el siguiente cuadro:

3 De conformidad al numeral 10 del articulo 246 del T.U.O de la Ley $\mathrm{N}^{\circ}$ 27444-Ley del Procedimiento Administrativo General, que dice textualmente:

"Artículo 246.- Principios de la potestadsancionadora administrativa

La potestad sancionadora de todas las entidadesestá regida adicionalmente por los siguientes principios especiales:

(.....)

10. Culpabilidad -

La responsabilidad administrativaes subjetiva, salvo los casos en que por ley o decretolegislativo se disponga la responsabilidad administrativa objetiva."

\section{EVOLUCION DEL PRINCIPIO DE CULPABILIDAD EN LA LPAG}

\begin{tabular}{|l|c|c|c|}
\hline $\begin{array}{l}\text { Manifestaciones } \\
\text { o Sub Principios } \\
\text { del Principio de } \\
\text { Culpabilidad }\end{array}$ & $\begin{array}{c}\text { Ley 27444 } \\
\text { (2001) }\end{array}$ & $\begin{array}{c}\text { D.Leg } \\
\mathbf{N}^{\mathbf{0}} \text { 1029 } \\
\text { (2008) }\end{array}$ & $\begin{array}{c}\text { D.Leg } \\
\mathbf{1 2 7 2} \\
\mathbf{( 2 0 1 6 )}\end{array}$ \\
\hline $\begin{array}{l}\text { Subprincipio } \\
\text { de Personalidad } \\
\text { de Sanciones } \\
\text { (Causalidad) }\end{array}$ & $\mathbf{X}$ & $\mathbf{X}$ & $\mathbf{X}$ \\
\hline $\begin{array}{l}\text { Subprincipio de } \\
\text { Culpabilidad en } \\
\text { Sentido Estricto } \\
\text { (Intencionalidad- }\end{array}$ & - & $\mathbf{X}$ & $\mathbf{X}$ \\
$\begin{array}{l}\text { Graduación de } \\
\text { Sanción) }\end{array}$ & & & \\
\hline $\begin{array}{l}\text { Subprincipio de } \\
\text { Responsabilidad } \\
\text { Subjetiva } \\
\text { (Dolo o Culpa- } \\
\text { Responsabilidad) }\end{array}$ & & - & $\mathbf{X}$ \\
\hline
\end{tabular}

Fuente: Ley 27444, Decreto Legislativo 1029 y Decreto Legislativo 1272

Elaboración: Propia

Sin embargo, si bien reconoce de manera expresa una manifestación del Principio de Culpabilidad, como es el Sub-Principio de Responsabilidad Subjetiva, no proscribe la Responsabilidad Objetiva, siendo que la regla general en los procedimientos administrativos sancionadores seria la responsabilidad subjetiva, mientras que la excepción seria la responsabilidad objetiva cuando la ley o decreto legislativo lo establezca ${ }^{4}$, tal como dice Morón Urbina (2017) "Por último, al establecerse la exigencia de la expresa habilitación por norma con rango de ley para la aplicación de la responsabilidad objetiva, esta se convierte en una figura excepcional, siendo en materia sancionadora la responsabilidad subjetiva" (página 451).

Complementariamente, es necesario indicar que dicha regla de la excepcionalidad de la responsabilidad objetiva ${ }^{5}$, por el carácter de

4 De conformidad a lo establecido en el numeral 13 de la Consulta Juridica $N^{\circ}$ 010-2017-JUS/DGDOJ de la actual Direccion General de Desarrollo Normativo y Calidad Regulatoria.

5 De conformidad al analisis conjunto del articulo II del Titulo Preliminar y el articulo 245 del TUO de la LPAG, lestablecido en el numeral 13 de la Consulta Juridica $N^{\circ}$ 034-2017JUS/DGDNCR de la actual Direccion General de Desarrollo Normativo y Calidad Regulatoria. 
garantía mínima o condición más favorable, es aplicable a las normas especiales que regulan procedimientos administrativo sancionadores, asimismo también sería aplicable la regla de responsabilidad objetiva relativa ${ }^{6}$, pues es aplicable los eximentes de responsabilidad a los casos de responsabilidad objetiva, pero eso solo es una aspiración de la LPAG, ya que dicha excepcionalidad de la responsabilidad objetiva podría ser inaplicada o exceptuada por normas con rango de ley, pues admitir lo contrario sería otorgarle a la LPAG un "valor supra legal del que carece expresamente" (Baca 2010, página 7). No pudiendo la LPAG otorgarse dicho valor a sí misma.

En ese sentido, considero que para que algunos preceptos de la LPAG, sean vinculantes a las normas especiales y al legislador, tendría que ser manifestaciones del contenido constitucional protegido de derechos fundamentales o constitucionales, lo cual implicaría que algunos preceptos de la LPAG tendría el carácter de Norma de Desarrollo Constitucional del ius puniendi en materia administrativa y pertenecerían al bloque de la constitucionalidad, convirtiéndolas en vinculantes y obligatorias al resto del ordenamiento jurídico, tanto al Legislador (Poder Legislativo), Administración Pública (Poder Ejecutivo) y la Administración de Justicia (Poder Judicial), de manera específica la regla de excepcionalidad de la responsabilidad objetiva que no derivaría de la LPAG (esta solo la positiviza a nivel legal) sino derivaría de la propia Constitución.

\section{Responsabilidad objetiva y su regulación en los procedimientos administrativos sancionadores regulados por normas especiales}

La incorporación expresa del principio de culpabilidad en la LPAG, trajo consigo el establecimiento de la regla general de responsabilidad subjetiva (dolo o culpa) y la excepcionalidad de la responsabilidad objetiva, por lo que es necesario hacer una síntesis de cómo se ha regulado en los procedimientos administrativos sancionadores establecidos por leyes especiales:

\footnotetext{
6 De conformidad a lo establecido en el numeral 12 de la Consulta Juridica N N $^{\circ}$ 010-2017-JUS/DGDOJ de la actual Direccion General de Desarrollo Normativo y Calidad Regulatoria.
}

En materia de contrataciones del Estado, la Ley de Contrataciones ${ }^{7}$, establece una responsabilidad objetiva como regla general y por excepción (justificar) responsabilidad subjetiva $^{8}$, sin embargo pareciera que el reglamento ${ }^{9}$, estableciera la responsabilidad objetiva absoluta, pues no permite el uso de los eximentes de responsabilidad establecidos en la LPAG.

En materia de Banca, Seguros y AFP, se establece un régimen diferenciado de responsabilidad en función a la gravedad de la infracción ${ }^{10}$, siendo que las infracciones leves se le aplica la responsabilidad subjetiva y para el caso de infracciones graves y muy graves la responsabilidad objetiva, asimismo hay una especie de delegación reglamentaria con parámetros.

En materia de datos personales, la ley de protección de datos personales ${ }^{11}$ establece de

7 De conformidad al numeral 50.1 del articulo 50 de la Ley de Contratraciones del Estado, modificada por el Decreto Legisaltivo $\mathrm{N}^{\circ} 1341$, que dice textualmente:

"Artículo 50. Infracciones y sanciones administrativas 50.1 El Tribunal de Contrataciones del Estado sanciona a los proveedores, participantes, postores, contratistas $\mathrm{y} / \mathrm{o}$ subcontratistas (....)

La responsabilidad derivada de las infracciones previstas en este artículo es objetiva, salvo en aquellos tipos infractores que admitan la posibilidad de justificar la conducta.

8 Dicha posicion ha sido confirmada, con las modificaciones del numeral 50.3 del articulo 50 de la Ley de Contrataciones del Estados, modificada por el Decreto Legislativo 1444, que dice textualmente:

"50.3 La responsabilidad derivada de las infracciones previstas en este artículo es objetiva, salvo en aquellos tipos infractores previsto en los literales a), b), h), y n) del numeral 50.1 del presente artículo.

9 De conformidad al numeral 226.3 del articulo 226.3 del Reglamento de la Ley de Contratraciones del Estado, modificada por el Decreto Legisaltivo $\mathrm{N}^{\circ} 1341$, que dice textualmente:

"Artículo 226.- Determinación gradual de la sanción 26.3. En los procedimientos sancionadores de competencia del Tribunal no se aplican los supuestos eximentes establecidos en el artículo 236-A de la Ley $\mathrm{N}^{\circ} 27444$, dada la determinación objetiva de la responsabilidad prevista en el numeral 50.1 del artículo 50 de la Ley."

10 De conformidad a la Primera Disposicion Complementaria Final del Decreto Legislativo $\mathrm{N}^{\circ} 1349$, que si bien no tuvo como principal objeto regular el procedimiento administrativo sancionador, dice textualmente:

"Primera.- Reglas para los procedimientos administrativos sancionadores iniciados por la Superintendencia de Banca, Seguros y Administradoras Privadas de Fondos de Pensiones En los procedimientos administrativos sancionadores iniciados por la Superintendencia de Banca, Seguros y Administradoras Privadas de Fondos de Pensiones se aplican las siguientes reglas:

a. Para las infracciones calificadas como leves, la responsabilidad administrativa es subjetiva.

b. Para el caso de las infracciones graves y muy graves, la responsabilidad administrativa es objetiva.

La Superintendencia reglamenta la debida aplicación de esta responsabilidad y su observancia en los procedimientos sancionadores."

11 De conformidad al articulo 38 de la Ley de Proteccion de Datos Personales, modificada por Decreto Legislativo $\mathrm{N}^{\circ}$ 
reforma administrativa constituciona

Relative strict llability for the purpose of the constitutional

administrative reform

manera ambigua la responsabilidad objetiva, al indicar que los administrados son responsables objetivamente por los incumplimientos de las obligaciones.

En materia ambiental, si bien la norma genérica (Ley General del Ambiente) habla de un régimen de responsabilidad objetiva, considero que este régimen solo es aplicado al ámbito civil ${ }^{12}$, pues no indica nada de responsabilidad administrativa de manera expresa, no pudiendo interpretar de manera extensiva (al ser una medida que restringe derechos), sin embargo en la norma especial de la Ley del Sistema Nacional de Evaluación y Fiscalización Ambiental (SINEFA) ${ }^{13}$, establece de manera indubitable, aunque sea por nomenclatura la responsabilidad objetiva, pues al igual que datos personales, establece de manera ambigua responsabilidad objetiva, al indicar que los administrados son responsables objetivamente.

Sin embargo, existen casos que a pesar de haberse aplicado la responsabilidad objetiva por la interpretación del término de forma objetiva, a raíz de la Casación 13233-2014LIMA $^{14}$, dicha interpretación seria incorrecta,

1353, dice textualmente:

"Artículo 38.- Tipificación de infracciones

Las infracciones (...)

Los administrados son responsables objetivamente por el incumplimiento de obligaciones derivadas de las normas sobre protección de datos personales".

12 De conformidad al articulo 144 de la Ley General del Ambiente(LGA)-Ley $\mathrm{N}^{\circ} 28611$ y modificatorias, no indica de manera expresa que se aplique dicho régimen de responsabilidad objetiva al ámbito administrativo, mas aun cuando se habla de indeminizacion propia del derecho civil, tal como dice textualmente:

Artículo 144.- De la responsabilidad objetiva

La responsabilidad (...), es objetiva. Esta responsabilidad obliga a reparar los daños ocasionados por el bien o actividad riesgosa, lo que conlleva a asumir los costos contemplados en el artículo 142 precedente, y los que correspondan a una justa y equitativa indemnización; los de la recuperación del ambiente afectado, así como los de la ejecución de las medidas necesarias para mitigar los efectos del daño y evitar que éste se vuelva a producir."

13 De conformidad al articulo 18 de la Ley del Sistema Nacional de Evaluacion y Fiscalizacion Ambiental(SINEFA)-Ley $\mathrm{N}^{\circ}$ 29325 y modificatorias, dice textualmente:

Artículo 18.- Responsabilidad Objetiva

Los administrados son responsables objetivamente por el incumplimiento de obligaciones derivadas de los instrumentos de gestión ambiental, así como de las normas ambientales y de los mandatos o disposiciones emitidas por el OEFA."

14 En la CASACION 13233-2014-LIMA se establede que la redacción de "forma objetiva"no esta vinculada al régimen de responsabilidad objetiva, tal como dice textualmente: “3.2. En tal contexto, definida la base fáctica, del análisis de la interpretación normativa realizada por la Sala de mérito, respecto al artículo 178 inciso 2 y la norma pertinente del artículo 165 del Texto Único Ordenado del Código Tributario, esta Sala Suprema advierte (...)correspondiendo por lo tanto desestimar la tesis de interpretación errónea postulada por pues la objetividad planteada no está en función al régimen de imputación o elemento del tipo infractor, sino por la objetividad de la pruebas o la neutralidad de la administración debe determina la responsabilidad del administrado, pudiendo evidenciar en materia tributaria ${ }^{15}$, en materia energética y minas (OSINERGMIN) ${ }^{16}$.

Siendoqueenmateriaderesponsabilidadfuncional sería el más debatible, pues se observa que la Ley Orgánica del Sistema Nacional de Control y de la Contraloría General de la República ${ }^{17}$ Ley $\mathrm{N}^{\circ} 27785$ y modificatorias, establece en un intento de limitar la responsabilidad objetiva que las infracciones pueden ser determinada de manera objetiva por el reglamento, por lo cual si asumiéramos, que se hubiera establecido un

las recurrentes, en tanto se basa en una interpretación restringida que construye una infracción sin considerar todos los elementos de la infracción tributaria que conforman el artículo 178.2, contraviniendo el artículo VIII del Título Preliminar del Código Tributario y el principio de tipicidad anotados precedentemente, invocando las impugnantes el artículo 165 del Código Tributario, como si dicho dispositivo excluyera de las conductas infractoras el elemento subjetivo para determinar la responsabilidad del administrado cuando la norma no está referida a la definición del tipo, sino a la forma objetiva que debe actuar la Administración para determinar la infracción "

15 De conformidad al articulo 165 del Codigo Tributario que dice:

"Artículo $165^{\circ}$.- DETERMINACION DE LA INFRACCION, TIPOS DE SANCIONES Y AGENTES FISCALIZADORES

La infracción será determinada en forma objetiva y sancionada administrativamente con (....)".

16 De conformidad al artículo $1^{\circ}$ de la Ley $\mathrm{N}^{\circ} 27699$, Ley Complementaria de Fortalecimiento Institucional de Osinergmin y posteriormente contemplado en el artículo $13^{\circ}$ de la Ley $\mathrm{N}^{\circ} 28964$, Ley que transfiere competencias de supervisión y fiscalización de las actividades mineras al Osinergmin, que dicen:

"Ley $\mathrm{N}^{\circ} 27699$

Artículo $1^{\circ}$.- Facultad de Tipificación

Toda acción u omisión que implique incumplimiento a las leyes, reglamentos y demás normas bajo el ámbito de competencia del OSINERG constituye infracción sancionable.

(....)

La infracción será determinada en forma objetiva y sancionada administrativamente,

Ley $\mathrm{N}^{\circ} 28964$

Artículo $13^{\circ}$. - Facultades del organismo competente

Para efectos de las funciones de supervisión y fiscalización de las actividades mineras, el Consejo Directivo del OSINERGMIN está facultado para tipificar los hechos y omisiones que configuran infracciones administrativas, asi como a graduar las sanciones.

La infracción será determinada en forma objetiva $\mathrm{y}$ sancionada administrativamente (....)"

17 De conformidad al articulo 46 de la Ley Orgánica del Sistema Nacional de Control y de la Contraloría General, modificada por la Ley 30742-Ley del Fortalecimiento de la Contraloria General de la Republica y del Sistema Nacional de Control, que dice:

"Artículo 46.- Conductas infractoras

Constituyen conductas infractoras graves o muy graves en materia de responsabilidad administrativa funcional, sujetas a la potestad sancionadora de la Contraloria General, las siguientes:

(....)

Estas infracciones pueden ser determinadas de forma objetiva, en los casos señalados en dicho reglamento. “. 
régimen de responsabilidad objetiva estaría desnaturalizando la excepcionalidad al establecer que la misma sea determinada por reglamento pero sin parámetros, más aun cuando si bien el Tribunal Constitucional ha establecido que la responsabilidad funcional es diferente a la disciplinaria, ha establecida que en esta última esta proscrita la responsabilidad objetiva.

Por último, existen casos que no conceptualizan bien el régimen de responsabilidad objetiva (al malinterpretar las presunciones de responsabilidad), aun cuando la ley no establece dicho régimen, vía reglamento establecen la misma ${ }^{18}$ o como el caso del derecho del consumidor, que al no regular de manera expresamente la responsabilidad objetiva, se aplicaría la responsabilidad subjetiva, a pesar de que habría implícitamente regulado una responsabilidad objetiva, hecho que se evidencia cuando establece los eximentes ${ }^{19}$.

\section{RESPONSABILIDAD SUBJETIVA Y OBJETIVA EN EL MARCO DE LA FILOSOFÍA DEL DERECHO Y TEORÍA GENERAL DEL DERECHO}

\section{Principio de culpabilidad y teorias de justicia a propósito de la responsabilidad subjetiva y objetiva}

El Principio de Culpabilidad, de manera específica la responsabilidad subjetiva (dolo o culpa) para determinar la infracción administrativa, y por ende su sanción, si bien

18 De conformidad al articulo 5 del Reglamento del Decreto Legislativo $\mathrm{N}^{\circ} 1277$, a pesar que el articulo $5^{\circ}$ del referido decreto solo habla de presunciones de responsabilidad que incluso admiten prueba en contrario, que dice:

"Art. 5 Responsabilidad por realización de comunicaciones malintencionadas

La atribución de la responsabilidad por la realización de comunicaciones malintencionadas es objetiva y recae en el titular del servicio, independientemente que sea quien efectúa o permita su realización, sin perjuicio de los supuestos de exclusión que resulten aplicables".

19 De conformidad a lo establecido en el articulo 104 del Codigo de Proteccion y Defensa del Consumidor-Ley N²9571 y normas modifcatorias, que dice:

"Artículo $104{ }^{\circ}$. Responsabilidad administrativa del proveedor.

El proveedor es administrativamente responsable por la falta de idoneidad o calidad, el riesgo injustificado o la omisión o defecto de información, o cualquier otra infracción a lo establecido en el presente Código y demás normas complementarias de protección al consumidor, sobre un producto o servicio determinado.

El proveedor es exonerado de responsabilidad administrativa si logra acreditar la existencia de una causa objetiva, justificada y no previsible que configure ruptura del nexo causal por caso fortuito o fuerza mayor, de hecho, determinante de un tercero o de la imprudencia del propio consumidor afectado." sostiene su validez y legitimidad en función a la norma (Constitución o Ley), la misma corresponde a una concepción de justicia, la responsabilidad subjetiva considera lo justo esta en funciona a la voluntad de la persona (o de la presunción de libertad frente al reto de la neurociencia ${ }^{20}$ ), se apoyaría en la concepción de justicia conmutativa, que considera justa la norma jurídica cuando la misma tiene su base en la convención o pacto es decir la voluntad, siendo que el parámetro de justicia se sustenta en la libertad.

Por otro lado, la responsabilidad objetiva, se apoyaría en la concepción de justicia distributiva, que considera justa la norma jurídica cuando la misma tiende a una asignación proporcional de los beneficios y cargas entre los miembros de una sociedad, siendo que el parámetro de justicia se sustenta en la igualdad.

\section{Responsabilidad subjetiva: ¿Regla o principio?}

La teoría de Robert Alexy, reformulando la teoría de Dworkin sobre los principios, señala que la diferencia entre principios y normas es de tipo cualitativa y lógica, proponiendo la denominada teoría estándar de los principios, conformada por "tres elementos: el mandato de optimización, la ley de colisión y la ponderación" (Portocarrero, 2016, página 46). Siendo el mandato de optimización el elemento central (y base de los otros dos) de su tesis sobre los principios.

Respecto al mandato de optimización, tal como dice Alexy (2017) "que son normas que ordenan que algo sea realizado en la mayor medida posible, dentro de los posibilidades jurídicas y reales (fácticas) existentes" (página 42) Y el referido mandato de optimización hace que los principios, a diferencia de las reglas, puedan cumplirse en diferente grados, siendo que el grado de cumplimiento va estar circunscritos a las posibilidades fácticas y jurídicas, por eso se dice que las reglas contienen "determinaciones" en el ámbito de lo fáctica o jurídicamente posible (se deben cumplir o no).

20 Se plantea ir del "axioma de la libertad" a la "presunción de libertad" frente a los retos de la neurociencia, ya que si asumismos el principio de culpabilidad, ha traido retos al derecho penal de igual manera traeria retos al derecho administrativo. 
Por lo que considero, que la responsabilidad subjetiva sería una regla pues establece un mandato de todo o nada, no hay manera de grados de cumplimiento, o se establece la responsabilidad por dolo o culpa, si asumiéramos dicha tesis, la regla de responsabilidad subjetiva podría ser derrotable, siendo compatible la excepción de la responsabilidad objetiva, sin embargo, seria admitir que la responsabilidad subjetiva no tendría rango constitucional.

Por otro lado, considero que si bien el principio de culpabilidad podría ser un principio en la concepción de Alexy, aunque no necesariamente la responsabilidad subjetiva tener dicho carácter, si por un momento se asumiese que ambos fueran principios (por ende derechos fundamentales) en el derecho administrativo sancionador, eso no impide que en algunos casos cedan vía ponderación, por ejemplo a fin de proteger el derecho al medio ambiente se podría establecer la responsabilidad objetiva como ha valido la Corte Constitucional colombiana, sin embargo el grado de afectación en abstracto seria alto con la sola limitación del sub principio de reserva ley, planteada por la LPAG, por lo que tendría que tener otras limitaciones para reafirmar su constitucionalidad.

\section{RESPONSABLILIDAD OBJETIVA EN EL MARCO DEL DERECHO CONSTITUCIONAL PERUANO Y COMPARADO}

\section{Principio de culpabilidad: ¿Derecho humano, derecho fundamental, derecho constitucional o derecho legal?}

El establecimiento de una diferenciación derecho fundamental y derecho humano, no va ser objeto en este trabajo sin embargo diremos que nuestra Constitución Política en aplicación del artículo $1^{\circ}$ (dignidad), artículo $3^{\circ}$ (derechos no enumerados) y la Cuarta Disposición Final y Transitoria de la Constitución (interpretación de derechos humanos), considera que tanto los derechos fundamentales y humanos son derechos constitucionales, no limitándose a los consagrados expresamente en el Capítulo I (concebidos como derechos fundamentales)

El Principio de Culpabilidad es reconocido como contenido implícito al principio de legalidad en materia penal ${ }^{21}$ establecido en el literal d) del numeral 24) del artículo $2^{\circ}$ de la Constitución Política del Perú, o derivado del principio de proporcionalidad de las penas ${ }^{22}$ establecido en el artículo $200^{\circ}$ del referido cuerpo normativo, tal como dice Santy (2017) cuando lo considera como un principio implícito al de presunción de inocencia, "Ahora bien este principio de culpabilidad, si bien no está reconocido de forma expresa en la actual Constitución Política de 1993; no obstante tácitamente, el citado principio, se presenta en el literal e) del numeral 24) del artículo $2^{\circ}$ de la Constitución Política del Perú, el cual considera como un contenido implícito que limita la potestad punitiva del Estado." (página 217).

Siendo de la misma opinión de Morón (2017), cuando nos habla de la positivización legal de algo reconocido jurisprudencialmente por el Tribunal Constitucional Peruano: "Sinceramente, lo que ha hecho la norma ha sido positivizar este principio, pero ya existía en reiterada y uniforme jurisprudencia del Tribunal Constitucional en asuntos administrativos (...)" (página 444).

Asimismo se reconoce como un subprincipio o manifestación el de la responsabilidad subjetiva $^{23}$ (dolo o culpa), sin indicar de manera expresa si esta forma parte del contenido constitucionalmente protegido, la importancia es vital pues si tuviera rango constitucional,tanto el principio de culpabilidad como el subrprincipio de imputación subjetiva o responsabilidad subjetiva, seria inconstitucionalidad al LPAG que permitiría el establecimiento de responsabilidad objetiva por ley o decreto legislativo, sin embargo si el subprinicpio de responsabilidad subjetiva fuera de rango legal o no formara parte del contenido constitucionalmente protegido del principio de culpabilidad, seria constitucional en abstracto o prima facie el establecimiento de la excepcionalidad de la responsabilidad objetiva en el derecho administrativo sancionador.

21 Conforme a lo establecido en el fundamento 28 de la STC $\mathrm{N}^{\circ}$ 0014-2006-AI /TC.

22 Conforme a lo establecido en el fundamento 32 de la STC $\mathrm{N}^{\circ}$ 0014-2006-AI /TC

23 Conforme a lo establecido en el fundamento 26 de la STC $\mathrm{N}^{\circ}$ 00014-2006-AI /TC. 


\section{Principio de culpabilidad en el derecho administrativo sancionador a través de la jurisprudencia del Tribunal Constitucional peruano}

El Tribunal Constitucional peruano, incorpora y desarrolla en su línea jurisprudencial al Principio de Culpabilidad en el ámbito penal, al considerarlo como una exigencia de la cláusula del Estado de Derecho y que se deriva como un principio constitucional implícito del límite de la potestad punitiva del Estado ${ }^{24}$, que si bien no tiene un reconocimiento constitucional expreso puede ser derivado del principio de proporcionalidad de las penas y de legalidad penal ${ }^{25}$.

Asimismo, asumiría como contenido constitucional protegido del principio de culpabilidad al subprincipio de responsabilidad subjetiva, cuando reconoce la proscripción de la responsabilidad objetiva en el ámbito penal $^{26}$, fundamentando la misma proscripción en que el elemento objetivo resulta atentaría al principio de culpabilidad y como colofón parecería indicar que solo es constitucional la pena fundada en elemento de dolo o culpa. ${ }^{27}$

En el ámbito administrativo sancionador, si bien el máximo intérprete de la constitución, ha considerado que el principio de culpabilidad le es aplicable, asumiendo la tesis de la unidad del derecho sancionador ${ }^{28}$, sin embargo luego precisa que la aplicación de diversos principios del derecho penal puede aplicarse con matices en el derecho administrativo sancionador, dentro de los cuales se menciona de manera referencial al principio de culpabilidad y la proscripción de la responsabilidad objetiva ${ }^{29}, \mathrm{y}$

24 Conforme a lo establecido en el fundamento 62 de la STC $\mathrm{N}^{\circ}$ 00102-2002-AI /TC.

25 Conforme a lo establecido en el fundamento 28 de la STC N $^{\circ}$ 03245-2010-HC /TC.

26 Conforme a lo establecido en el fundamento 28 de la STC N ${ }^{\circ}$ 03245-2010-HC /TC

27 Conforme a lo establecido en el fundamento 28 de la STC $\mathrm{N}^{\circ}$ 03245-2010-HC /TC.

28 Conforme a lo establecido en el fundamento 28 de la STC $\mathrm{N}^{\circ}$ 02050-2002-AA /TC.

29 Es necesario indicar que en en 1 fundamento 12 de la STC $\mathrm{N}^{\circ}$ 01873-2009-PA/TC, nuestro máximo interprete de la Constitución no fija una posicion clara e indubitable si la responsabilidad subjetiva tendria rango constitucional y de la proscripción de la responsabilidad objetiva como lo hace en el ámbito penal, ya que parece detallar de manea referencial o enunciativa de dicho principio como es concebido en el derecho penal, mas aun cuando al final la definición que da no corresponde a la responsabilidad subjetiva sino al de tipicidad " Principio de culpabilidad, (.....) esto es, que solo se puede imponer una sanción si es que la conducta prohibida y su consecuencia están previstas legalmente." respecto al mismo solo señala que la dificultad de aplicarla, estaría en función de que en el derecho penal existiría predictibilidad de las sanciones a título de dolo o culpa.

Por lo que, considero que nuestro Tribunal Constitucional, no ha sido categórico ni ha podido evaluar la constitucionalidad de la responsabilidad objetiva en el derecho administrativo sancionador (no disciplinario ${ }^{30}$ ), ya que la proscripción de responsabilidad objetiva solo es mencionada de manera referencial al concepto de culpabilidad, a diferencia de que, si es categórico respecto a la inconstitucionalidad de la responsabilidad objetiva en el ámbito penal ${ }^{31}$ llendose más allá de lo establecido en el Código Penal, sin embargo si se ha pronunciado de la constitucionalidad de la responsabilidad objetiva en el ámbito civil (por ende no sería perse arbitrario sino más gravoso $)^{32}$.

30 En el fundamento 21 de la STC 2868-2004-AA/TC solo habla implícitamente de una proscripción de la responsabilidad objetiva al solo admitir la responsabilidad subjetiva pero solo al ámbito penal o disciplinario, asimismo cuando hace el analisis de constitucionalidad sobre la proscripción de la responsabilidad objetiva solo hace mención a una de las manifestaciones del principio de culpabilidad que es el de personalidad de sanciones, tal como dice textualmente:

"21. (....) un limite a la potestad sancionatoria del Estado está representado por el principio de culpabilidad. Desde este punto de vista, la sanción, penal o disciplinaria, solo puede sustentarse en la comprobación de responsabilidad subjetiva del agente infractor de un bien juridico. En ese sentido, no es constitucionalmente aceptable que una persona sea sancionada por un acto o una omisión de un deber jurídico que no le sea imputable."

31 En el fundamento 63 y 65 de la STC 2868-2004-AA/TC establece como constitucional solo la responsabilidad subjetiva en el ámbito penaly por endela inconstitucionalidad de la responsabilidad objetiva que va mas alla del Codigo Penal, tal como dice textualmente:

"63. (....)

Es decir, es inconstitucional el sentido interpretativo que excluye del tipo cualquier referencia a la responsabilidad o culpabilidad del sujeto. Por lo tanto, los jueces no pueden condenar, al amparo de dicho artículo $2^{\circ}$ del Decreto Ley $\mathrm{N}{ }^{\circ} 25475$, a una persona por el solo hecho de que se haya lesionado o puesto en peligro los bienes jurídicos señalados en la misma disposición legal sin tomar en cuenta el análisis de su culpabilidad.

65. Por ello, el Tribunal considera que es inconstitucional la norma implicita que se deriva de la frase "El que provoca, crea o mantiene", en la medida en que no prevé la responsabilidad subjetiva, esto es, la intención del agente como la susceptible de reprocharse penalmente."

$32 \mathrm{Si}$ bien siempre se ha sostenido frente al argumento de aplicación en el derecho administrativo sancionador de la responsabilidad objetiva seria inconstitucionalidad, por ser la misma "abitraria" o "incompatible con el Estado Social y Democratico de Derecho", sin embargo sobre la base del efecto de irradiación de los derechos fundamentales, si asimismos que la responsabilidad subjetiva tiene rango constitucional debe ser aplicada a todos los ámbitos inclusive el ámbito civil, sin embargo su aplicación demostraría que no es "arbitrario perse" o "incompatible con el Estado Social y Democratico de Derecho", sino solo mas gravoso, sobre la constitucionalidad de la responsabilidad objetiva en el ámbito civil podemos evidenciarla en el fundamento 25 de la STC 00001-2005-AI tal como dice: 


\section{Principio de culpabilidad en el derecho administrativo sancionador a través del derecho comparado}

En el derecho administrativo sancionador español, podemos evidenciar que la posición mayoritaria de la doctrina, reconoce que se ha partido de la responsabilidad objetiva para luego reconocer el principio de culpabilidad, de manera específica la responsabilidad subjetiva, tal como lo sostiene Garcia (2005).

Sin embargo, una posición minoritaria en el otro extremo encontramos a Nieto (2012), que no reconoce el rango constitucional al principio de culpabilidad para el derecho administrativo sancionador, sino que la denomina "una creación jurisprudencial" (página 427), en esa línea de establecer al principio de culpabilidad como uno de orden legal, considera que la regla general es la responsabilidad objetiva salvo que la ley de manera expresa establezca la responsabilidad subjetiva.

Por otro lado, el Tribunal Constitucional español, ha sido claro en su línea jurisprudencial, al indicar que el principio de culpabilidad rige en materia de infracciones administrativas, por ser estas manifestaciones del ius puniendi del Estado $^{33}$, así como reconoce su rango constitucional al derivarse de los principios de legalidad y prohibición del exceso reconocidos en el artículo 25 de la Constitución española o de las exigencias inherentes al Estado de Derecho ${ }^{34}$, y siguiendo esa línea argumentativa establece la proscripción de la responsabilidad objetiva en el ámbito administrativo sancionador siendo solo posible la sanción administrativa si esta se sustenta con la concurrencia de dolo o culpa ${ }^{35}$; sin embargo es interesante ver que no se admite la constitucionalidad de la excepcionalidad de la responsabilidad objetiva, pero si se admite la constitucionalidad de la excepcionalidad de la responsabilidad solidaria ${ }^{36}$, a pesar de que ambos casos tienen efectos en el subprincipio de responsabilidad subjetiva y el sub principio de personalidad de las sanciones, ambos manifestaciones del principio de culpabilidad.

"25. Consecuentemente, el Tribunal Constitucional estima que el artículo $29^{\circ}$ de la Ley 27181, que establece que la responsabilidad civil derivada de los accidentes de tránsito causados por vehículos automotores es objetiva, conforme al Codigo Civil, no resulta inconstitucional (....)"

33 Conforme lo establecido en la STC 150/1991.

34 Conforme lo establecido en la STC 76/1990.

35 Conforme lo establecido en la STC 5397/1998.

36 Conforme lo establecido en la STC 181/2014.
En el derecho administrativo sancionador colombiano, la Corte Constitucional colombiana en un primer momento reconoce que esta proscrita la responsabilidad objetiva por contravenir los principios de dignidad humana y de culpabilidad, asumiendo que este último formaría parte del contenido del principio de presunción de inocencia ${ }^{37}$, sin embargo luego en su línea jurisprudencial reconoce que la responsabilidad subjetiva es aplicada con matices en el derecho administrativo sancionador y de manera excepcional la constitucionalidad de la responsabilidad objetiva con ciertos límites más allá del de reserva de ley ${ }^{38}$.

Finalmente, en Ecuador, podemos ver la máxima consagración de la responsabilidad objetiva, pues la propia constitución ecuatoriana en su artículo 396, establece la responsabilidad objetiva en materia ambiental, que considero pudiera aplicarse en el derecho administrativo sancionador. ${ }^{39}$.

\section{RESPONSABLILIDAD OBJETIVA EN EL MARCO DE LA CORTE INTERAMERICANA DE DERECHOS HUMANOS (CIDH)}

En el marco del Sistema Interamericano de Derechos Humanos, evidenciamos que la Convención Americana de Derechos Humanos el artículo 8 titula como "garantías judiciales", siendo que en el numeral 8.1 consagraría entre otros el "derecho al debido proceso" en sede judicial y en el numeral 8.2 el derecho a la "presunción de inocencia" en materia penal.

Sin embargo la Corte Interamericana de Derechos Humanos (CIDH), ha extendido la garantía del debido proceso no solo a los procesos judiciales, sino a los procedimientos administrativos sancionadores, en un primer momento a través de diversas opiniones consultivas tales como la OC- $9 / 87^{40}$ y la OC-

37 Conforme lo establecido en el fundamento Sentencia C-597/96.

38 Conforme lo establecido en el fundamento 6 de la Sentencia C-690/96, fundamento 3 de la Sentencia C-616/02 y el fundamento 5 de la Sentencia C-595/10.

39 Conforme lo estableceria el articulo 396 de la Constitucion Politca del Ecuador que dice textualmente:

"Art. 396. - (...) La responsabilidad por daños ambientales es objetiva. Todo daño al ambiente, además de las sanciones correspondientes, implicará también la obligación de restaurar integralmente los ecosistemas e indemnizar a las personas y comunidades afectadas."

40 Conforme se evidencia en el fundamento 27 de la OC-9/87. 
$11 / 90^{41}$ y luego en el Caso Baena Ricardo vs Panamá $(2001)^{42}$, que ha sido parte de su línea jurisprudencial en diversos casos ${ }^{43}$.

En esa línea, la Corte ha extendido la presunción deinocenciaalos procedimientosadministrativos sancionadores, tal como desarrolla en el Caso Suárez Ordoñez vs Guatemala (2016) ${ }^{44}$, y si bien en el ámbito administrativo no se ha pronunciado; en el ámbito penal se pronuncia que el derecho de presunción de inocencia comprende la demostración fehaciente de culpabilidad y carga de la prueba en la parte acusadora, por lo que en esa línea va contra la convención asumir la presunción de culpabilidad y determinar la responsabilidad sobre la base de dicha presunción, sin embargo el término culpabilidad no es entendido como criterio de responsabilidad subjetiva, sino vinculado a la carga de la prueba y que la responsabilidad debe estar debidamente probada más allá de toda duda razonable, tal como lo desarrolla en el en el Caso Zegarra Marín vs Perú (2017) ${ }^{45}$.

Finalmente, respecto a si el establecimiento de la responsabilidad objetiva en el procedimiento administrativo sancionador, contravendría de la Convención Americana, la Corte se ha pronunciado en el Caso Leopoldo López vs Venezuela $(2011)^{46}$, al desestimar como violación a la presunción de inocencia el haber sido sancionado administrativamente por responsabilidad objetiva y validar el argumento de la Sala Política Administrativa del Tribunal Supremo de Venezuela sobre la constitucionalidad de la responsabilidad objetiva en el derecho administrativo sancionador venezolano.

41 Conforme se evidencia en el fundamento 28 de la OC$11 / 90$.

42 Conforme se evidencia en los fundamentos 106-107, 115 123-132 del Caso Baena Ricardo vs Panama (2001).

43 Conforme se evidencia en los fundamentos 67-71 del Caso Tribunal Constitucional vs Peru (2001), fundamentos 101110 del Caso Ivcher vs Peru (2001), fundamentos 147150 del Caso Yatama vs Nicaragua (2005), fundamentos 115-119 del Caso Claude Reyes y otros vs Chile (2006), fundamento 208 del Caso Escher vs Brasil (2009), fundamentos 108 y $145-147$ del Caso Velez Loor vs Panama (2010), fundamentos 117-120 del Caso Chocron vs Venezuela (2011), fundamentos 116-119 del Caso Bardani Duarte vs Uruguay (2011), fundamentos 129-132 y 157 del Caso Familia Pacheco vs Bolivia (2013), fundamentos 171 y 184-186 del Caso Tribunal Constitucional vs Ecuador (2013), fundamento 210 del Caso Galindo Cardenas vs Peru (2015); y fundamento 208 del Caso Wong vs Peru (2015).

44 Conforme se evidencia en los fundamentos 71-75 del Caso Suarez Ordoñez vs Guatemala (2016).

45 Conforme se evidencia en los fundamentos 121-126, 138-140, 146-148 y 153-156 del Caso Zegarra Marin vs Peru (2017)

46 Conforme se evidencia en los fundamentos 124, 130 y 131 del Caso Leopoldo Lopez vs Venezuela (2011).
Finalmente, es necesario indicar que en el ámbito del derecho comunitario europeo, el principio de culpabilidad (sub principio de responsabilidad subjetiva) no ha sido reconocido como un principio del ordenamiento comunitario europeo, ya que el Tribunal de Justicia de la Unión Europea (TJUE) lo ha negado no solo en el derecho administrativo sancionador, sino inclusive en el derecho penal permitiendo excepcionalmente como dice Bueno (2012) un "régimen de responsabilidad penal objetiva" (página157). Por otro lado en el Derecho Europeo (comunitario y no comunitario) la Convención Europea de Derechos Humanos no ha reconocido de manera expresa el principio de culpabilidad ni mucho menos su subprincipo de responsabilidad subjetiva, pues en el numeral 6.2 del artículo 6 solo reconoce la presunción de inocencia y el termino de culpabilidad ${ }^{47}$ tal como el caso de la Convención América, es respecto y no responsabilidad subjetiva sino a la carga de la prueba, hecho que no ha sido cambiado por el Tribunal Europeo de Derechos Humanos (TEDH) cuando lo desarrolla en el Caso Vlieeland Boddy y Marcelo Lanni vs España (2016) ${ }^{48}$

\section{REFORMA CONSTITUCIONAL A FIN DE EXPLICITAR LA POTESTAD SANCIONADORA DE LA ADMINISTRACION PÚBLICA Y LA RESPONSABILIDAD OBJETIVA}

La Constitución Política del Perú, es la máxima norma del ordenamiento jurídico (artículo 51) consagrando la supremacía constitucional ${ }^{49}$, sin embargo la potestad sancionadora de la Administración Publica no se encuentra regulada de manera expresa en la Constitución y aunque el debate sobre su por contravenir el "principio de división de poderes" (Danós,

47 Conforme a lo contemplado en el numeral 6.2 del articulo 6 de la Convencion Americana de Derechos Humanos que dice:

"Articulo 6

Derecho a un proceso equitativo

(....)

2. Toda persona acusada de una infraccion se presume inocente hasta que su culpabilidad haya sido legalmente declararada".

48 Conforme se evidencia en los fundamento 38 del Caso Vlieeland Boddy y Marcelo Lanni vs España (2016) que dice: “38. De entrada, el TEDH recuerda que se menosprecia la presunción de inocencia si una decisión judicial que afecta a un procesado refleja la sensación de que éste es culpable, cuando en realidad su culpabilidad no ha sido previamente establecida legalmente (Allen c. Reino Unido [GC], no 25424/09, § 93, CEDH 2013)."

49 Conforme a lo establecido en el fundamento 3 de la STC $\mathrm{N}^{\circ}$ 05854-2005-AA/TC (Caso Lizana Puelles). 
1995, página 150), ha sido legitimada por razones pragmáticas, el desarrollo y expansión del derecho administrativo hace necesaria su reconocimiento constitucional, por lo que considero necesaria la respectiva reforma constitucional a fin de reconocer dicha potestad.

Es necesario indicar, que las reformas que se han planteado de la potestad sancionadora de la Administración Pública en el Perú, van hacia modificar el literal d) del numeral 24 del artículo 2 de la Constitución Política del Perú, a fin de que sea tal como lo reconoce el artículo 25 de la Constitución Española, como se describiría en el siguiente cuadro:

\begin{tabular}{|c|c|}
\hline $\begin{array}{c}\text { Constitución Política } \\
\text { del Perú }\end{array}$ & Constitución española \\
\hline $\begin{array}{l}\text { Artículo } 2^{\circ} \text {.- Toda persona } \\
\text { tiene derecho: } \\
\text { (...) } \\
\text { 24. A la libertad y a la } \\
\text { seguridad personales. En } \\
\text { consecuencia: } \\
\text { (....) } \\
\text { d. Nadie será procesado } \\
\text { ni condenado por acto } \\
\text { u omisión que al tiempo } \\
\text { de cometerse no esté } \\
\text { previamente calificado en } \\
\text { la ley, de manera expresa } \\
\text { e inequívoca, como } \\
\text { infracción punible; ni } \\
\underline{\text { sancionado con pena no }} \\
\text { prevista en la ley. }\end{array}$ & $\begin{array}{l}\text { 1. Nadie puede } \\
\text { ser condenado o } \\
\underline{\text { sancionado por }} \\
\text { acciones u omisiones } \\
\text { que en el momento } \\
\text { de producirse no } \\
\text { constituyan delito, } \\
\text { falta o infracción } \\
\underline{\text { administrativa, }} \text { según } \\
\text { la legislación vigente en } \\
\text { aquel momento. }\end{array}$ \\
\hline
\end{tabular}

Fuente: Constitución Política del Perú y Constitución Española

Elaboración: Propia

Sin embargo, considero que a fin de dotar la autonomía científica al derecho administrativosancionador y darle la relevancia constitucional respectiva, es necesario desarrollar un capitulo específico del ius puniendi, autónomo y distinto a lo desarrollado en el literal d) del numeral 24 del artículo 2 de la Constitución Política del Perú, a fin de buscar un punto de equilibrio entre las garantías necesarias a los administrados y la eficacia de la potestad sancionadora de la administración, como sería establecer la constitucionalidad de la excepcionalidad de la responsabilidad objetiva en el derecho administrativo sancionador.

\section{LEY DE DESARROLLO CONSTITUCIONAL A FIN DE ESTABLECER LOS LIMITES DE LA RESPONSABILIDAD OBJETIVA RELATIVA}

Estableciéndose que luego de la reforma constitucional a fin de explicitar la potestad sancionadora de la Administración Pública y la constitucionalidad de la excepcionalidad de la responsabilidad objetiva en el derecho administrativo sancionador, es necesario desarrollar dichos preceptos, que serían a través de una ley de desarrollo constitucional, considero que dicha norma al formar parte del bloque de constitucionalidad, seria vinculante al resto de ordenamiento jurídico, ya que las normas especiales si no garantizan ese mínimo o se exceptúan de su aplicación, contravendrían no dicha norma, sino la propia constitución, siendo invalidas las sanciones que se sustenten en normativa, por otro lado la especialidad del derecho administrativo sancionador y su efecto de irradiación en la Administración Pública, considero que es necesario separarla de la LPAG por la especialidad e importancia del tema como lo ha existido por el Código de Protección y Defensa del Consumidor, y ayudaría a formar conciencia de la autonomía del Derecho Penal que tiene sus propios códigos tanto de la parte sustantiva como procesal, por lo que es necesario dotarle de dicha importancia que se traduce en la importancia que se da en las universidades en país ${ }^{50}$.

En ese sentido, la ley de desarrollo constitucional también desarrollaría los criterios mediante el cual se pueda garantizar la excepcionalidad de la responsabilidad objetiva relativa, mediante el cual el legislador tendrá parámetros, mediante límites formales $\mathrm{y}$ materiales $^{51}$ al momento de emitir leyes

50 En el Peru a pesar del desarrollo en toda la Administracion Publica, si bien existen cursos sobre protección al consumidor, ambiental, regulacion y otros, no existe a nivel de pregrado "Cursos de Derecho Administrativo Sancionador", sino que el mismo forma parte de cursos de derecho adminsitrativo u otro, ni menos decir de una maestria en derecho administrativo sancionador como si la existe en derecho penal.

$51 \mathrm{El}$ único limite formal que la LPAG ha establecido para la responsabilidad objetiva es el subprincipio de reserva de ley, pues solo mediante ley se puede establecer la responsabilidad objetiva. 
especiales que regulen sus procedimientos administrativos sancionadores.

\section{CONCLUSIONES}

El Principio de Culpabilidad, comprende los sub principios de personalidad de sanciones y responsabilidad subjetiva, siendo que respecto a esta última implica la proscripción de la responsabilidad objetiva.

El Principio de Culpabilidad, específicamente el sub principio de responsabilidad subjetiva, ha sido incorporado jurisprudencialmente al derecho administrativo sancionador, y luego se ha positivizado en la LPAG, sin la proscripción de la responsabilidad objetiva, que es permitida como excepción por ley o decreto legislativo.

En ese línea, se plantea dotar de una autonomía científicaalderechoadministrativosancionador, ya que con esta autonomía a nivel dogmático daría contenido al giro pragmático que se ha propuesto, pues permitiría romper el dogma de la proscripción de la responsabilidad objetiva pero establecería su naturaleza excepcional por ser una medida restrictiva del Ius Puniendi, ya que el objetivo principal no es proscribir las medias restrictivas y discrecionales, sino la arbitrariedad del ius puniendi del Estado.

En ese sentido, es necesario indicar que las normas especiales han regulado de manera variada la responsabilidad objetiva en los procedimientos administrativos sancionadores, pero en muchos casos se han desnaturalizado del carácter excepcional que tendría que tener la responsabilidad objetiva.

En el Derecho Constitucional peruano, podemos ver que el principio de culpabilidad ha sido reconocido $\mathrm{e}$ incorporado al derecho administrativo sancionador, pero lamentablemente el subrprincipio de responsabilidad subjetiva, nuestro tribunal constitucional no ha sido tenido oportunidad de manifestarse expresamente sobre constitucionalidad o no en algún caso en específico, solo existiendo algunas sentencias en materia disciplinaria.

En el Derecho Constitucional Comparado, vemos diversos casos el caso español que solo admite como constitucional la responsabilidad y proscribe la responsabilidad objetiva; y por otro lado el caso colombiano que admite como constitucional la responsabilidad subjetiva pero permite excepcionalmente la responsabilidad objetiva, siendo que finalmente tenemos el caso ecuatoriano que lo consagra a nivel constitucional de manera expresa en materia ambiental.

En el Sistema de Derechos Humanos, podemos evidenciar que la responsabilidad objetiva no ha sido considera que contravendría la Convención Americana de Derechos Humanas, y en el caso del derecho europeo, vemos que en el Derecho Comunitario, el Tribunal de Justicia de la Unión Europea (TJUE) lo ha negado no solo en el derecho administrativo sancionador, sino inclusive en el derecho penal permitiendo excepcionalmente como dice un régimen de responsabilidad penal objetiva, por otro lado en la Convención Europea de Derechos Humanos, no está contemplada y el término culpabilidad Tribunal Europeo de Derechos Humanos como carga de la prueba.

Complementariamente, en el marco de la filosofía del derecho, la responsabilidad subjetiva se apoyaría en la concepción de justicia conmutativa, mientras que la responsabilidad objetiva, se apoyaría en la concepción de justicia distributiva; por otro lado en el marco de la teoría general del derecho, tanto si el sub principio de responsabilidad subjetiva seria regla o principio en ambos casos podría ser factible como excepción a la regla o vía ponderación respectivamente, el establecimiento de la responsabilidad objetiva.

Después de todo este desarrollo, considero que es necesario realizar la reforma constitucional, a fin de explicitar la potestad sancionadora de la Administración Pública y la excepcionalidad de la responsabilidad objetiva relativa.

En ese fin, para delimitar la potestad sancionadora de la Administración Publica, es necesaria una ley de desarrollo constitucional que formaría parte del bloque de constitucionalidad, a fin de que sea vinculante al resto del ordenamiento jurídico, pues si una ley especial la contravendría implicaría una vulneración a la propia constitución, y las sanciones que se fundamente en dicha ley serian nulas; siendo que tendría como efecto adicional potenciar la autonomía científica del derecho administrativo sancionador que es necesario que converse con la oferta educativa en el país. 
Finalmente, dicha ley de desarrollo, deberá desatar uno de los nudos giordanos, que es la excepcionalidad de la responsabilidad objetiva relativa en el derecho administrativo sancionador, por lo que se establecerán los parámetros a través de límites formales y materiales que permitan su constitucionalidad en las leyes especiales.

\section{FUENTES DE INFORMACIÓN}

\section{Fuentes bibliográficas}

Alexy, R. (2007). Teoria de los derechos fundamentales. Madrid, España: Centro de Estudios Políticos y Constitucionales.

Gómez, M. y Sanz, I. (2010). Derecho Administrativo Sancionador-Parte General. Navarra, España: Aranzadi.

Morón, J. C. (2017). Comentarios a la Ley del Procedimiento Administrativo General. Lima, Peru: Gaceta Juridica.

Portocarrero, J. A. (2016). La ponderación y la autoridad en el derecho. Madrid, España: Marcial Pons.

Rojas, H. F. (2015). Fundamentos del Derecho Administrativo Sancionador. Lima, Peru: Instituo Pacifico S.A.C.

\section{Fuentes hemerográficas}

Danós, J. (1995). Notas acerca de la potestad sancionadora de la administración publica. Revista de Ius et Veritas, N 10, Página 149-160.

Santy, L.V. (2017). El Prinicpio de Culpabilidad en la Jurisprudencia del Tribunal de Contrataciones del Estado. Revista Dialogo con la Jurisprudencia, $\mathrm{N}^{\circ}$ 224, Página 215-222.

\section{Fuentes Electrónicas}

Bueno, A. (2012). El (Imperfecto) Sistema de Garantias del Derecho Administrativo Sancionador de la Union Europea. A propósito de la Potestad Sancionadora del Banco Central Europeo. Revista de Derecho de la Union Europea $\mathrm{N}^{\circ} 23$. Recuperado del sitio de internet: http://revistas.uned.es/index.php/ REDUE/article/view/12605

Baca, V. S. (2010). ¿Responsabilidad subjetiva u objetiva en materia sancionadora? Una propuesta de respuesta a partir del ordenamiento peruano? Recuperado del sitio de internet http://www.mpfn.gob.pe/ escuela/contenido/actividades/docs/2271 responsabilidad_subjetiva_u_objetiva_en_materia_sancionadora.pdf.

Corte Suprema de Justicia del Peru (2016). Casación 13233-2014-LIMA. Recuperado del sitio de internet https://legis.pe/fijan-criteriosinterpretacion-configuracion-infraccionestributarias-jurisprudencia-corte-idh/

Corte Constitucional colombiana (1996-2010). Sentencia C-597/96. Sentencia C-690/96. Sentencia C-616/02. Sentencia C-595/10. Recuperados del sitio de internet: http://www. corteconstitucional.gov.co/relatoria/

Corte Interamericana de Derechos Humanos (1987-2016). OC-9/87.OC-11/90. Recuperados del sitio de internet: http://www.corteidh. or.cr/cf/Jurisprudencia2/busqueda_opiniones_ consultivas.cfm?lang $=\mathrm{es}$

Caso Baena Ricardo vs Panama (2001). Caso Tribunal Constitucional vs Peru (2001). Caso Ivcher vs Perú (2001). Caso Yatama vs Nicaragua (2005). Caso Claude Reyes y otros vs Chile (2006). Caso Escher vs Brasil (2009). Caso Vélez Loor vs Panamá (2010). Caso Chocron vs Venezuela (2011). Caso Bardani Duarte vs Uruguay (2011). Caso Familia Pacheco vs Bolivia (2013). Caso Tribunal Constitucional vs Ecuador (2013). Caso Galindo Cardenas vs Perú (2015). Caso Wong vs Peru (2015). Caso Suárez Ordoñez vs Guatemala (2016). Caso Zegarra Marin vs Perú (2017). Caso Leopoldo López vs Venezuela (2011). Caso Vlieeland Boddy y Marcelo Lanni vs España (2016). Recuperados del sitio de internet: http://www.corteidh.or.cr/ cf/Jurisprudencia2/index.cfm?lang=es

Dirección General de Desarrollo Normativo y Calidad Regulatoria. Consulta Juridica $\mathrm{N}^{\mathrm{o}}$ 005-2015-JUS/DGDOJ. Consulta Juridica $\mathrm{N}^{\mathrm{o}}$ 010-2017-JUS/DGDOJ. Consulta Juridica $\mathrm{N}^{\mathrm{o}}$ 010-2017-JUS/DGDOJ. Recuperado del sitio de internet: http://pisaq.minjus.gob.pe:8080/ opileg_web/ConsultaWebAction_verWeb 